\title{
CLOSTRIDIUM DIFFICILE: ISOLATION AND CHARACTERISTICS
}

\author{
S. HAFIZ* AND THE LATE C. L. OAKLEY \\ Department of Microbiology, Medical School, University of Leeds, LS2 9NL
}

\section{Plate VIII}

REFERENCES to the isolation and study of Clostridium difficile are rare. We had done some preliminary investigations when we learned from Dr S. D. Elsden of the Food Research Institute, Norwich, that strains of $C$. difficile could deaminate phenylalanine, first to parahydroxyphenylacetic acid (as most clostridia that attack this substrate do), and then decarboxylate the $p$ hydroxyphenylacetic acid to $p$-cresol. None of the other clostridia that we examined were able to perform the latter step.

We assumed that an organism that produced $p$-cresol must necessarily be resistant to it, and we applied this information to the isolation of $C$. difficile.

\section{MATERIALS AND MethodS}

Strains. We had altogether 30 strains: three old laboratory strains (nos. G173, 238 and 311), three from the American Type Culture Collection (ATCC nos. 17857, 17858 and 9689), six we had ourselves isolated on cresol-free media from stools of infants (labelled nos. R1-R6), and 18 that we isolated on cresol-containing medium from human and animal faeces. The following observations are mainly based on our studies of the old laboratory strains (for convenience labelled N1-N3 and the ATCC strains (labelled N4-N6). However, the freshly isolated strains have been extensively examined and shown to be identical with these reference strains of $C$. difficile.

Cultivation. Our own early isolates were obtained from the faeces of babies less than 1

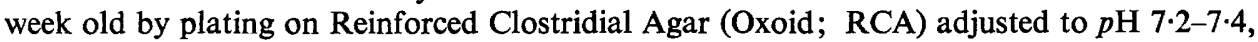
and incubating the cultures in an anaerobic jar for $72 \mathrm{~h}$. Colonies resembling those of $C$. difficile were then picked off and subcultured in Reinforced Clostridial Medium (Oxoid; RCM). Later isolates were obtained by lightly emulsifying $0.1 \mathrm{~g}$ of faeces, dung, sand or mud in $20 \mathrm{ml}$ of RCM containing $0.2 \%$-cresol.

For the study of the effect of cresols and phenol on growth, a $10 \%(v / v)$ aqueous solution or emulsion of the material to be tested was diluted in RCM to give final concentrations of $0 \cdot 1,0 \cdot 2,0 \cdot 3,0.4$ and $0.5 \%(\mathrm{v} / \mathrm{v})$. Higher concentrations were made by direct additions of phenol or cresol to RCM, and dissolved by steaming; but as the distribution of cresols in $\mathrm{RCM}$ in concentrations of $1 \%$ and over was not uniform, as shown by the presence of a thin surface film, we abandoned the use of media containing concentrations of phenol greater than $0.5 \%$.

Proteose Peptone water plus $1 \%$ sugar or other substrate, with phenol red as indicator, was used for examination of the biochemical action of $C$. difficile, cultures being incubated

Received 19 Mar. 1975; revised version accepted 22 Sept. 1975.

* Present address: Department of Medical Microbiology, University of Sheffield, Sheffield, S10 2RX.

J. MED. MICROBIOL.-VOL. 9 (1976) 
anaerobically at $37 \mathrm{C}$ for a maximum of 40 days. Frazier's medium (nutrient agar + gelatin $0.4 \%(\mathrm{w} / \mathrm{v}))$ was used for the demonstration of gelatinase production (Frazier, 1926).

For the production of the toxin and other soluble antigens Proteose Peptone Broth (Oxoid), Robertson's cooked meat medium and RCM were used.

All media were used fresh if possible; before use, liquid media prepared more than 4 days earlier were boiled and cooled just before inoculation; solid media were used on the day of their preparation or stored in an anaerobic jar.

Preparation of immunising suspensions and antisera to $C$. difficile. Antisera against strains N1-N6 were prepared in rabbits by intravenous injection of live washed bacilli. Pre-immunisation samples of the rabbit sera contained no demonstrable antibody against C. difficile.

A 48-h culture of $C$. difficile in RCM was centrifuged at 3000 r.p.m. for 30 min. and the deposited organisms suspended in saline, washed four times in normal saline and finally resuspended in saline to a standard concentration of $3 \times 10^{8}$ organisms per $\mathrm{ml}$ by reference to previously standardised nephelometer readings.

After preliminary test bleedings, young adult New Zealand rabbits were given $1 \mathrm{ml}$ of such a suspension of $C$. difficile intravenously. A second dose of $1 \mathrm{ml}$ was given by the same route on the 8th day and subsequently $1 \mathrm{ml}$ was given every 3rd day for 6 weeks, for a total of 14 injections. When a suitable antibody level was obtained, blood was taken and the serum was separated.

Filtrates. In a similar way, antisera were produced in rabbits against crude toxin preparations from strains of $C$. difficile (see below).

Agglutination tests. Rabbit sera were diluted 1 in 10, and serial two-fold dilutions to 1 in 5120 prepared and set out in $0.5-\mathrm{ml}$ volumes in agglutination tubes; to each tube was added an equal volume of a suspension of killed organisms, prepared by heating at $100^{\circ} \mathrm{C}$ for $30 \mathrm{~min}$. and standardised to contain $10^{\circ}$ organisms per $\mathrm{ml}$. The mixtures were incubated at $37 \mathrm{C}$ for $2-3 \mathrm{~h}$ and the results were then read. Sera were absorbed with all six strains and retested for agglutinins; two absorptions with the same strain were found to be necessary to remove all the homologous agglutinins.

Toxin production: 100-ml volumes of Proteose Peptone Broth were seeded with $C$. difficile and incubated anaerobically for $72 \mathrm{~h}$. The supernate obtained after centrifugation at 3500 r.p.m. for $30 \mathrm{~min}$. was Seitz-filtered and the crude toxin precipitated from the cultures by the slow addition of an equal volume of $70 \%$ ammonium sulphate solution. The precipitate was dialysed against distilled water for $48 \mathrm{~h}$ and finally dissolved in $1 / 20$ of the original volume in sterile saline. This concentrated crude toxin preparation was used for initial neutralisation experiments.

Toxins. The lethal effects of the toxin preparations, obtained from 72-h cultures as described above, were investigated in mice. Graded doses of crude toxin or the purified preparation were given intravenously to groups of 10 mice. In the first experiment, six groups of 10 mice received doses of crude toxin ranging from $0.4 \mathrm{ml}$ to $0.2 \mathrm{ml}$ and seven groups of 10 mice received purified toxin in doses ranging from $5.0 \mathrm{mg}$ to $0.5 \mathrm{mg}$. To test the necrotic effect of toxin, doses of crude filtrate from 0.025 to $0.25 \mathrm{ml}$ were injected intradermally into guinea-pigs. The haemolytic action of the crude toxin was tested by adding $0.5 \mathrm{ml}$ of serial dilutions to a series of tubes containing $0.5 \mathrm{ml}$ of a $2 \%$ suspension of horse red cells. The results were read after $2 \mathrm{~h}$ in a water bath at $37^{\circ} \mathrm{C}$. Apart from the substitution of horse for ox red cells, the method was that used by Smith (1963). In tests for hyaluronidase, bovine synovial fluid was used as substrate. These tests, and tests for deoxyribonuclease, were done with the Acra test as described by Oakley and Warrack (1951).

\section{RESULTS}

All the strains of $C$. difficile that we tested were strictly anaerobic grampositive bacilli varying in shape from a very short thick form to a large bacillus measuring $(2 \cdot 5-5.9) \times(0.3-1.5) \mu \mathrm{m}$ with rounded ends. The organisms were 
sluggishly motile and had a few peritrichous flagella. Spores, which were not numerous, were subterminal.

\section{Laboratory cultural appearances}

When grown on RCA, all strains produced colonies that varied from irregular, finely scalloped and greyish to regular, smooth, opaque, greyish, flat and pitted. Pitting of the fully developed colony seems characteristic.

The appearances in RCM, which contains $0.05 \%$ of agar, are consistent and characteristic. Following the inoculation of $0.5 \mathrm{ml}$ of a suspension of $10^{3}$ bacteria per $\mathrm{ml}$ into $25 \mathrm{ml}$ of RCM, growth begins to appear as a small tear drop (or groups of them) $1-1.5 \mathrm{~cm}$ below the meniscus, with a tiny bubble at the centre (fig. 1); this is presumably the highest level at which the organism can grow. The "tear drop" gradually grows downwards by finger-like projections (fig. 2) which appear to be held up by bubbles between them; later the general appearance shows a marked resemblance to a miniature cornfield (fig. 3). The strings of growth will resist gentle shaking; later the growth tends to form a mushroom-like cloud (fig. 4) which finally settles down to the bottom, leaving the supernate clear and nearly sterile (fig. 5).

The foregoing growth changes in RCM can be varied by varying the inoculum; thus, a larger, more actively growing inoculum will produce the observed series of changes more rapidly, whereas a smaller or less active one will slow down the sequence. In the main, the changes take from 96-168 h. We have tested the effect of bottles of different shapes and sizes on this characteristic growth in an attempt to make photography easier, but the Universal container appears to be the only successful one.

\section{Survival of $C$. difficile in liquid medium}

Cultures of $C$. difficile in RCM stored at room temperature $\left(16^{\circ} \mathrm{C}\right)$ remained viable for a year. Cultures in RCM stored in the cold room at $3^{\circ} \mathrm{C}$ and cultures in cooked-meat medium, stored at room temperature or at $3^{\circ} \mathrm{C}$, were still viable when last tested at the end of 3 years.

\section{Biochemical studies}

The 30 strains available for study showed very uniform biochemical reactions. Thus, acid was produced in the first 24-96 h of culture, with gas later, from glucose, laevulose, dextrose, fructose, galactose, mannose, raffinose, xylose, aesculin and mannitol. Maltose, sucrose, glycogen, soluble starch and sorbitol were fermented by all strains with production of acid only; lactose and rice starch were not fermented by any strain. A minority of strains also fermented arabinose and rhamnose with the production of acid and gas, and a few strains fermented maize starch and potato starch, dulcitol and $m$-inositol with the production of acid only. 
Occasionally no action was detectable before 10 days, so incubation for 20 days was considered advisable. All strains reduced nitrates to nitrites; no strain produced hydrogen sulphide or indole nor broke down DL-methionine.

Gelatinase. When grown on Frazier's medium, all strains, especially when freshly isolated, appeared to attack gelatin; some took up to 30 days to do so. No gelatinase could be demonstrated in any of the culture filtrates.

Hyaluronidase. All 30 strains of $C$. difficile produced hyaluronidase. Yields varied from about 4 to about 40 effective doses per $\mathrm{ml}$ of crude toxin filtrate.

Deoxyribonuclease. No strain produced deoxyribonuclease.

Haemolytic activity. When tested as described (see Methods), the crude filtrate had a haemolytic titre of 16 .

\section{Effect of cresols and phenols on growth of $C$. difficile in Reinforced Clostridial Medium}

All strains grew in RCM containing up to $0.4 \% p$-cresol; other species of Clostridium and all the aerobes we tested failed to grow even in $0.1 \% p$-cresol. When $c .10000$ organisms of $C$. difficile were mixed with $10 \mathrm{~g}$ of faeces and $1 \mathrm{~g}$ of the mixture was emulsified in $\mathrm{RCM}$ containing $0.2 \% p$-cresol, only $C$. difficile grew, although anaerobic culture of similar material on cresol-free medium produced a copious overgrowth of associated bacteria. The use of cresol in this way made it much easier for us to isolate $C$. difficile in pure culture at the first attempt from baby faeces, soil, camel or horse or donkey dung, sand and mud.

A comparison of the viable counts of cultures in $p$-cresol-containing medium and control RCM showed some slowing of growth in the former. Thus the maximum counts were reached after incubation for $20 \mathrm{~h}$ in control cultures without cresol; the maximum count in cresol-containing medium was delayed by a further $4 \mathrm{~h}$. There was a steady fall in the maximum viable counts with increasing concentrations of $p$-cresol: at a concentration of $0.5 \%$ the viable count remained stationary for $8 \mathrm{~h}$ and then fell rapidly (fig. 6).

Similar results were obtained with $o$ - and $m$-cresol and with phenol.

As our later isolations were made in $\mathrm{RCM}+0.2 \% p$-cresol, it was natural that these organisms should be resistant to $p$-cresol, and it might be claimed that all we had done was to select $p$-cresol-resistant mutants. However, all the strains nos. N1-N6 and our own nos. R1-R6 had been isolated on media free from phenol or cresol and were nevertheless just as resistant to $p$-cresol and phenol as strains isolated in media containing $0.2 \% p$-cresol.

\section{Agglutination tests}

In a preliminary study of the agglutination reactions of six rabbit antisera against the six strains used as antigens, each of the sera agglutinated not only the homologous strain but also all the others, though to different titres. Shared antigens therefore appear to exist. Absorption tests showed that although most 
antigens were shared, there appears to be one specific to each strain (the table); the antigens are evidently numerous.

\section{Toxins}

Lethal toxins are produced in small amounts by strains N1-N5 of $C$. difficile; strain N4 was the best toxin producer (4 MHD50 per ml). Preliminary tests suggested that the lethal toxins were all antigenically similar, but yields were very low and more precise work was not possible at this stage.

A necrotising effect was demonstrated by intradermal injections in guineapigs; the reactions varied from a diffuse swelling of the injected area, often with a faint lilac discolouration of the skin, to small yellowish necrotic patches surrounded by diffuse swelling. The dose of material that would produce these effects would often kill the guinea-pig.

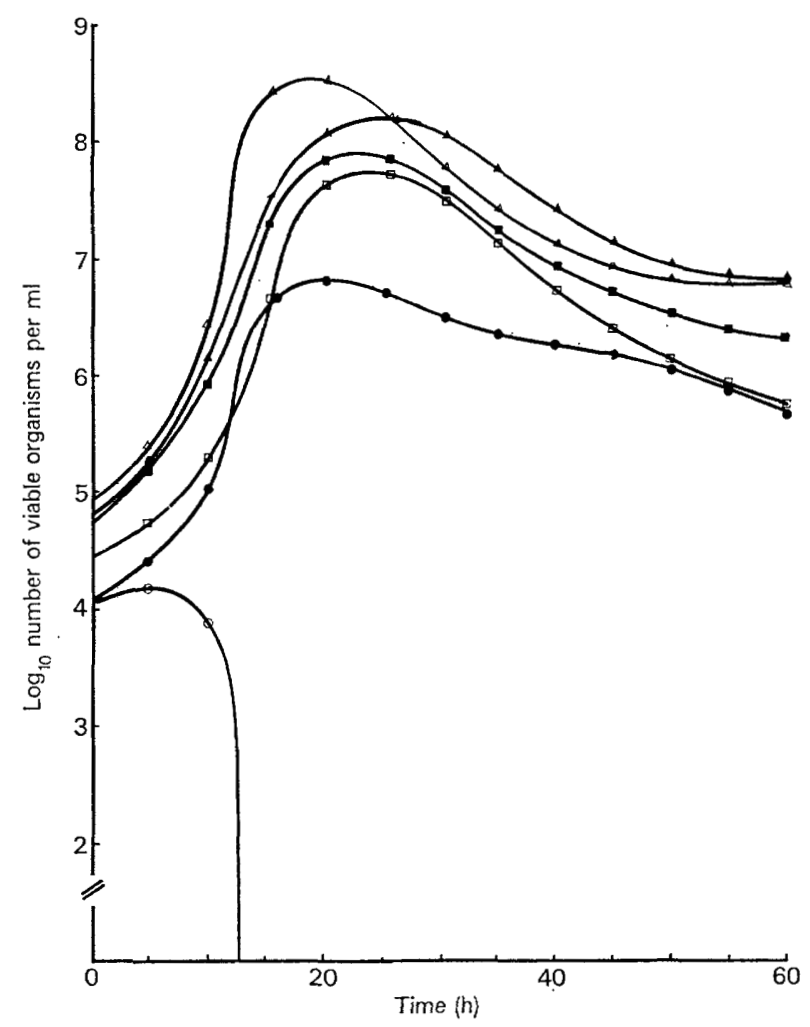

FIG. 6.-Viable counts at various times after inoculation of Clostridium difficile into culture media containing graded concentrations of paracresol: $\triangle-\triangle=$ control (no $p$-cresol); $\boldsymbol{\Delta}-\boldsymbol{\Lambda}=$ $0 \cdot 1 \%$; $\square=0.2 \% ; \square-\square=0.3 \%$; $=0.4 \% ; 0-0=0.5 \%$.

\section{Discussion}

In 1935, Hall and O'Toole reported the isolation of a new obligate anaerobic bacillus from meconium and faeces of about $40 \%$ of normal infants aged from 
TABLE

Agglutinin-absorption studies with sera prepared against strains of Clostridium difficile

\begin{tabular}{|c|c|c|c|c|c|c|c|}
\hline \multirow{2}{*}{$\begin{array}{l}\text { Serum prepared } \\
\text { against } \\
\text { strain no. }\end{array}$} & \multirow{2}{*}{$\begin{array}{c}\text { Strain } \\
\text { used for } \\
\text { absorption }\end{array}$} & \multicolumn{6}{|c|}{$\begin{array}{c}\text { Agglutination titre obtained with the stated serum } \\
\text { against strain no. }\end{array}$} \\
\hline & & N1 & $\mathrm{N} 2$ & N3 & N4 & N5 & N6 \\
\hline N1 & $\begin{array}{l}\ldots{ }^{*} \\
\text { N1 } \\
\text { N2 } \\
\text { N3 } \\
\text { N4 } \\
\text { N5 } \\
\text { N6 }\end{array}$ & $\begin{array}{r}2560 \\
-\dagger \\
640 \\
640 \\
1280 \\
640 \\
1280\end{array}$ & $\begin{array}{l}320 \\
= \\
= \\
40 \\
- \\
40\end{array}$ & $\begin{array}{c}640 \\
- \\
80 \\
- \\
160 \\
- \\
160\end{array}$ & $\begin{array}{l}320 \\
- \\
- \\
20 \\
- \\
\overline{40}\end{array}$ & $\begin{array}{l}320 \\
= \\
\overline{2} \\
\frac{-}{160}\end{array}$ & $\begin{array}{l}80 \\
= \\
= \\
- \\
20\end{array}$ \\
\hline $\mathrm{N2}$ & $\begin{array}{l}\text { N1 } \\
\text { N2 } \\
\text { N3 } \\
\text { N4 } \\
\text { N5 } \\
\text { N6 }\end{array}$ & $\begin{array}{l}320 \\
= \\
\overline{40} \\
\overline{40}\end{array}$ & $\begin{array}{r}2560 \\
640 \\
- \\
640 \\
640 \\
640 \\
640\end{array}$ & $\begin{array}{l}160 \\
= \\
= \\
= \\
= \\
=\end{array}$ & $\begin{array}{l}640 \\
80 \\
- \\
80 \\
= \\
-\end{array}$ & $\begin{array}{l}320 \\
= \\
- \\
- \\
- \\
-\end{array}$ & $\begin{array}{c}640 \\
320 \\
- \\
80 \\
80 \\
40 \\
-\end{array}$ \\
\hline N3 & $\begin{array}{l}\text { N1 } \\
\text { N2 } \\
\text { N3 } \\
\text { N4 } \\
\text { N5 } \\
\text { N6 }\end{array}$ & $\begin{array}{c}640 \\
-40 \\
- \\
80 \\
40 \\
20\end{array}$ & $\begin{array}{l}320 \\
- \\
= \\
20 \\
- \\
-\end{array}$ & $\begin{array}{r}1280 \\
160 \\
320 \\
- \\
640 \\
320 \\
160\end{array}$ & $\begin{array}{l}320 \\
-20 \\
- \\
- \\
-\end{array}$ & $\begin{array}{l}320 \\
= \\
\overline{2} \\
= \\
=\end{array}$ & $\begin{array}{l}320 \\
= \\
= \\
- \\
20\end{array}$ \\
\hline $\mathrm{N} 4$ & $\begin{array}{l}\text { N1 } \\
\text { N2 } \\
\text { N3 } \\
\text { N4 } \\
\text { N5 } \\
\text { N6 }\end{array}$ & $\begin{array}{c}640 \\
- \\
80 \\
80 \\
- \\
40 \\
-\end{array}$ & $\begin{array}{l}320 \\
= \\
20 \\
= \\
=\end{array}$ & $\begin{array}{l}320 \\
20 \\
= \\
= \\
-\end{array}$ & $\begin{array}{r}2560 \\
320 \\
640 \\
640 \\
-640 \\
320\end{array}$ & $\begin{array}{l}320 \\
- \\
- \\
\overline{4} \\
= \\
-\end{array}$ & $\begin{array}{l}640 \\
40 \\
\overline{2} \\
20\end{array}$ \\
\hline N5 & $\begin{array}{l}\text { N1 } \\
\text { N2 } \\
\text { N3 } \\
\text { N4 } \\
\text { N5 } \\
\text { N6 }\end{array}$ & $\begin{array}{l}320 \\
- \\
- \\
20 \\
40 \\
-\end{array}$ & $\begin{array}{r}640 \\
80 \\
-40 \\
40 \\
-80\end{array}$ & $\begin{array}{l}320 \\
20 \\
= \\
20 \\
- \\
-\end{array}$ & $\begin{array}{l}320 \\
20 \\
= \\
= \\
=\end{array}$ & $\begin{array}{r}1280 \\
320 \\
160 \\
320 \\
320 \\
- \\
160\end{array}$ & $\begin{array}{r}640 \\
40 \\
40 \\
20 \\
80 \\
- \\
-\end{array}$ \\
\hline N6 & $\begin{array}{l}\text { N1 } \\
\text { N2 } \\
\text { N3 } \\
\text { N4 } \\
\text { N5 } \\
\text { N6 }\end{array}$ & $\begin{array}{l}160 \\
= \\
= \\
= \\
=\end{array}$ & $\begin{array}{l}320 \\
40 \\
= \\
= \\
= \\
-\end{array}$ & $\begin{array}{l}320 \\
80 \\
20 \\
= \\
= \\
=\end{array}$ & $\begin{array}{r}640 \\
40 \\
20 \\
40 \\
- \\
- \\
-\end{array}$ & $\begin{array}{l}640 \\
20 \\
40 \\
40 \\
= \\
=\end{array}$ & $\begin{array}{r}2560 \\
1280 \\
640 \\
640 \\
320 \\
320 \\
-\end{array}$ \\
\hline
\end{tabular}


1 to 10 days. The organism grew slowly and was readily overgrown by associated bacteria. Hall and O'Toole named it Bacillus difficilis, because of the difficulty experienced in isolating and studying it. Snyder (1937) reported the isolation of 17 similar strains and confirmed many of Hall and O'Toole's original observations. In 1940 Snyder reported isolating the organisms from the faeces of $15 \%$ of infants aged 10 weeks -1 year. No further reports of $C$. difficile appeared for 20 years; then, in $1960 \mathrm{McBee}$ isolated it from the intestinal tract of a Weddell seal killed in the Antarctic, and in 1962 Smith and King recorded its presence in human infections. Danielsson, Lambe and Persson (1972) studied the immune response to a mixed infection in a patient with a peri-rectal abscess from which Bacteroides fragilis subsp. fragilis and C. difficile were isolated. These workers demonstrated by the indirect immunofluorescence technique that the patient had antibodies to $C$. difficile.

After the observation that $C$. difficile produces $p$-cresol, we began to study the addition of $p$-cresol to culture media for the selective isolation of the organism. These investigations showed that the organism could be isolated in pure culture from grossly contaminated inocula by the use of RCM containing $0 \cdot 1-0.4 \% p$-cresol. Preliminary studies on the frequency of the organism in the urogenital tract of patients attending venereal-disease clinics and controls (Hafiz et al., 1975) showed that the presence of $C$. difficile may be obscured by the overgrowth of less exacting organisms unless a selective medium is used. From these observations it seems probable that the distribution of the organism, at least in small numbers, is wider than we had previously suspected. The clinical significance of the presence of small numbers of the organism remains to be established.

\section{SUMMARY}

Clostridium difficile can be grown readily in Reinforced Clostridial Medium (RCM) containing $0 \cdot 1-0.4 \%$ of $o-, m$ - or $p$-cresol, or phenol. We recommend $0.2 \%$ of phenol or $p$-cresol in RCM for the isolation of this organism.

The characteristic " cornfield " growth in RCM in 25-ml Universal containers is described.

Glucose, fructose, galactose, mannose, raffinose, aesculin and mannitol are fermented with production of acid and gas; maltose, sucrose, glycogen, soluble starch and sorbitol are fermented with production of acid only. Lactose and rice starch are not fermented by any strain, and DL-methionine is not attacked. Nitrate is reduced to nitrite. Hydrogen sulphide and indole are not produced. Gelatin is attacked by all strains, but in some cases prolonged incubation is required. Hyaluronidase is produced, but not deoxyribonuclease. A lethal toxin appears to be produced.

Strains possess shared and strain-specific antigens.

Dr Hafiz acknowledges the help and guidance received from Professor M. G. McEntegart of the Department of Medical Microbiology, The University of Sheffield, in the preparation of this paper. 


\section{REFERENCES}

Danielsson, D., Lambe, D. W. And Persson, S. 1972. The immune response in a patient to an infection with Bacteroides fragilis sub species fragilis and Clostridium difficile. Acta path. microbiol. scand., B80, 709.

FrazIER, W. C. 1926. A method for the detection of changes in gelatin due to bacteria. J. infect. Dis., 39, 302.

Hafiz, S., McEntegart, M. G., Morton, R. S. and Waitkins, S. A. 1975. Clostridium difficile in the urogenital tract of males and females. Lancet, 1, 420.

HALL, I. AND O'TOOLE, E. 1935. Intestinal flora in newborn infants with a description of a new pathogenic anaerobe Bacillus difficilis. Am. J. Dis. Child., 49, 390.

MCBeE, R. H. 1960. Intestinal flora of some Antarctic birds and mammals. J. Bact., 79, 311.

OAKLEY, C. L. AND WARRACK, G. H. 1951. The Acra test as a means of estimating hyaluronidase, deoxyribonuclease and their antibodies. J. Path. Bact., 63, 45.

Smith, H. W. 1963. The haemolysins of Escherichia coli. J. Path. Bact., 85, 197.

SMITH, L. DS. AND KING, E. O. 1962. Occurrence of Clostridium difficile in infections of man. J. Bact., 84, 65 .

SYNDER, M. L. 1937. Further studies on Bacillus difficilis (Hall and O'Toole). J. infect. Dis., 60, 223.

SNYDER, M. L. 1940. The normal faecal flora of infants between two weeks and one year of age. J. infect. Dis., 66, 1 . 


\section{CLOSTRIDIUM DIFFICILE}

1
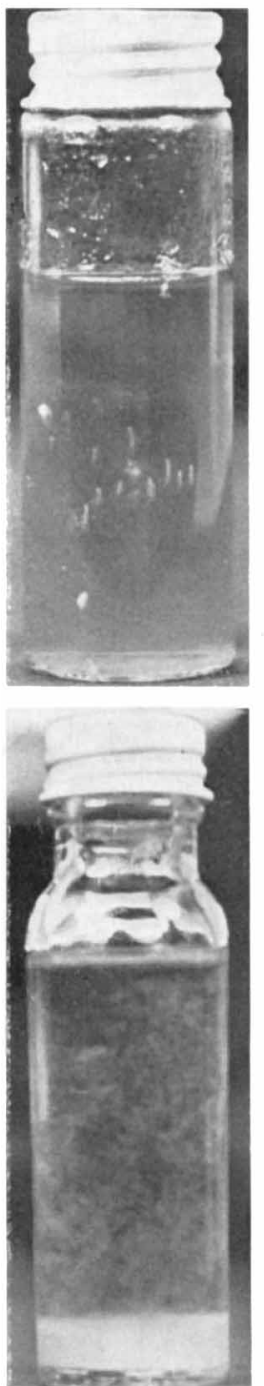

2
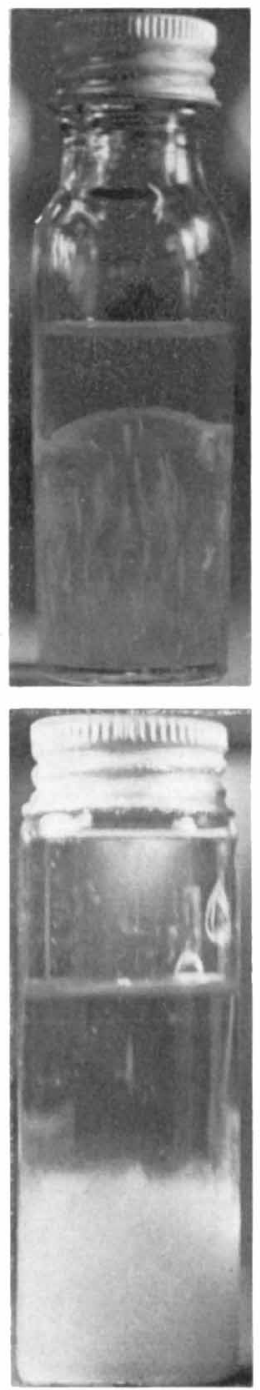

5
3

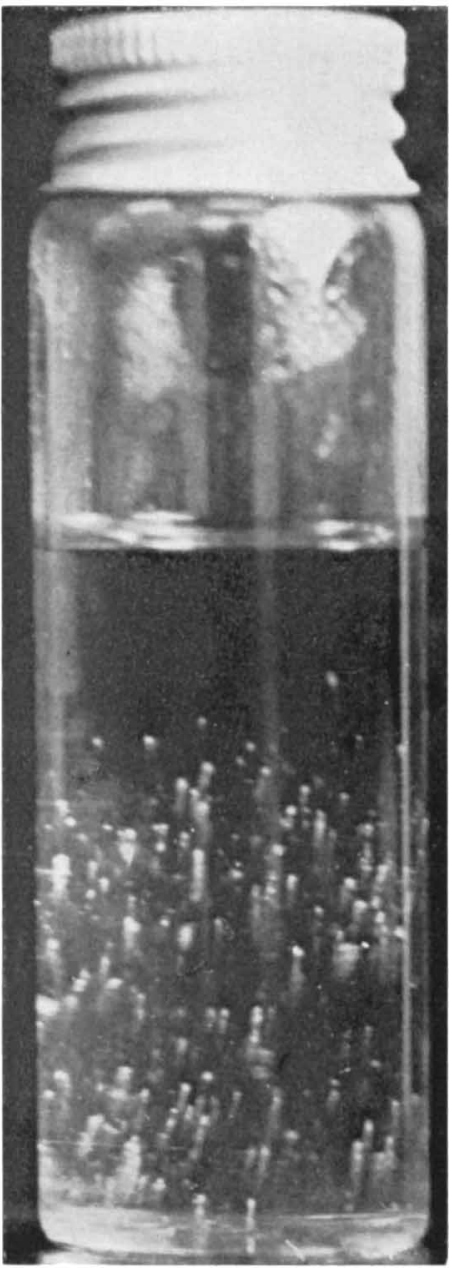

